\title{
Co-work between University Teachers: Is it Possible to Build a Common Language?
}

\author{
http://dx.doi.org/10.3991/ijac.v7i3.3983 \\ Luísa Soares \& Dulce Pacheco \\ University of Madeira, Funchal, Portugal
}

\begin{abstract}
Some of the ideas/categories that resulted from this work suggest a common language should be built between different professionals who work together: i) Consider the human side of technology; ii) Important behaviours for team work are complementarity, cohesion and synchronization; iii) attention to details motivates students; iv) Stimulate new experiences/new thoughts; v) Master four different abilities: inform, educate, inspire and entertain; vi) The essential will always remain, although times are changing and new fields of science are coming; vii) The web changed the way we work and learn, and that's more important than the way we interact with the contents of the web; viii) Technology should improve teaching skills; ix) Working together can be painful, so eliminating personnel barriers could result in a good cooperation/collaboration; $x$ ) Team building; xi) Create relevant contents; xii) Build channels to reach all over the world; xiii) Bridging programs can be very useful after a first graduation course where the main abilities from one area are already consolidated; xiv) Commitment to the team goals; xv) Psychologists are needed in teams and $x v$ ) The dream university is the one that has pleasant and large spaces to be used by people, and to inspire them.
\end{abstract}

Index Terms - bridging, language and university teachers.

\section{INTRODUCTION}

Steve Jobs said, "Don't live in a bubble. Connect ideas from different fields.". This proposal shares some reflections between a psychologist and several colleagues from different fields. Recently, Madeira University launched the challenge to offer a post graduation course called Bridging Program in Human Aspects of Technology. The students and teachers are from different backgrounds, Psychology, Design and The Arts. The creation of a "common bridge language" between so many different fields, and the formation of a new bridging field in science is one of our goals. This is how science grows: Exploring thoughts and ideas; forming good teamwork; and letting something new be born.

The future of Universities will be interdisciplinary work. Working together with scientists from different fields, discerning from different points of view to reach a solution to an entirely new kind of human problem.

It is not uncommon to come across difficulties with understanding what different scientists/university teachers/researchers present when working on ideas or solutions to a certain problem. Usually, these professionals defend their scientific field with a lot of rigidity, not attending other points of view. This work wants to focus on the problem of working together with people from different scientific fields.
The Bologna process in European higher education emphasizes that group work must be recognized in the learning process, developing several skills in students. To function collectively, a group needs to have some key attributes like collective perception, shared aims, interdependence, social organization, interaction, cohesiveness, and membership (Davies, 2009). In higher education, and among student group work, it is commonly understood as a process in which groups of people interdependently share responsibility for the outcome of a semester-long course task, and project (Strom \& Strom, 2002). The benefits of group learning are well identified and widely researched in literature. Shimazoe and Aldrich (2010) state several benefits of group work, such as promotion of deep learning, promotion of social skills and civic values, teaching a high order of thinking skills, promoting personal growth and positive attitudes toward autonomous learning. Group work allows people engage in discussion and take responsibility for their own ideas. It facilitates active exchange of ideas, increases motivation among participants, and develops a better understanding of diverse cultural background.

Despite the great number of advantages, Davies (2009) also shows some problems that may arise in group works, such as motivational issues, ethnic mixes, the complexity of the task, the recognition of individual effort, the group size, encouragements and penalties, or even the "freerider" effect - the group member who obtains reward for no effort.

University teachers must be both researchers and teachers, and need cultural diversity training. Hughes (2002) argues that many higher education institutes are not adequately prepared to provide the essential requirements and support for effective group working.

To understand the dynamics of group co-work it is important to notice that all groups have a "life cycle". This cycle is comprised of three stages. The first one is the design and development stage, when groups form and start developing competencies, rules, and strategies and establish the normative aspects of their work. This stage also helps to develop social skills and team building. The second stage is the operation stage, when the task is clarified; and group performance is monitored through peer evaluation and feedback, for example. The leader develops a crucial role in these stages, but particularly in this one, since he must intervene quickly and effectively when problems arise, rearranging group members. The last stage is when the leader gives adequate feedback, and work results are discussed. At this point it is important that the reward system is consistent. It should satisfy both individual and collective needs. As Shimazoe and Aldrich (2010) say, the leaders' roles are very important, since they play significant roles in guiding, monitoring and 
PAPER

framing group activities. Moreover, they need to motivate the group to participate and ensure that they work appropriately. Thus, they must be positive models, explaining the benefits from working in-group, and they need to maintain a helpful and encouraging attitude.

As the success of a team depends on the interaction among the team members, it is important to think about the role of diversity, and how it affects team performance. Some studies, such as Hamilton, Nickerson and Owan (2003) have shown that team diversity, with respect to individual capabilities, has a significant positive impact on productivity. Thus, it is clear that each member has much to give to the group: sharing talents and abilities.

Group leadership represents one of the characteristics of effective group performance. Group effectiveness includes the quality of the group performance and the perceived satisfying of individual group member needs. Most groups contain certain individuals who are primarily responsible for defining group goals, and for developing and structuring the group to accomplish tasks. A central responsibility of group leaders is to raise the collective efficacy of the group. If group members believe their team is capable of achieving goals, they are more likely to choose to engage the task (Zaccaro, 1996). The effect of group leadership also depends on the type of group and the task in handling. Leaders who are high in task-focused leadership create a strong situation that restricts group members from expressing their individual values, and reduces group conflicts. Leaders who are high in personfocused leadership, in contrast, legitimize individual group member's perspectives, creating a weaker group situation that frees the expression of a group members' values, increasing group conflicts (Klein, Knight, Zieger, Lim, \& Saltz, 2011). Indeed, we would argue that effective leadership processes represent perhaps the most critical factor in the success of groups. In fact, we know surprisingly little about how leaders create and manage effective groups (Frasen, 2012). On the other hand, there are few studies on the perception of the group members about the leader. A meta-analysis of research on the relationship between group member satisfaction and leadership style showed that groups prefer democratic leadership instead of autocratic leadership, although the effect on member satisfaction is moderated by group composition (Foels, Driskell, Mullen, \& Salas, 2000).

\section{IS IT POSSIBLE TO BUILD A COMMON LANGUAGE?}

The present work aims to increase the discussion about teamwork between researchers, and therefore, some ideas given by a group of researchers are presented. Those ideas were organized into categories and can be seen as guidelines to improve co-work between researchers.

\section{A. Scientists participants}

Five scientist participants collaborated in this "working study" from two different fields: social sciences and exact sciences. Their ages vary from $28-45$ years old. An open question interview was shared. The scientists wrote down their answers, which were then categorized into categories presented below in a guideline/recommendation format.

\section{B. Recommendations /Guidelines}

Some of the ideas/categories that resulted from these dialogues suggest guidelines to take into account when working together with scientists from different fields: i. Always consider the human side of technology; people need to reduce the technology that they use, so they won't damage the personal contacts, as we are social beings who need to interact in presence to become happier.

ii. Important behaviors for team work are complementarity, cohesion and synchronization; reduce personal barriers for effective cooperation and collaboration

iii. Attention to details motivates people;

iv. Stimulate new experiences/new thoughts; We should inform and educate, but also promote selfthinking and allow differences and seed the need for discovery.

v. Master four different abilities: inform, educate, inspire, and entertain; teaching is not only transmitting knowledge. The emotional side is very important.

vi. The essential will always remain, although times are changing and new fields of science are coming. Genius and simplicity are usually very close.

vii. The web changed the way we work and learn, and that's more important than the way we interact with the contents of the web. On the Internet students can find all the information they need. In the classroom they need new experiences, new examples and ways to put together all the data. They want to be part of the learning; of the experience.

viii. Technology should improve teaching skills. An iPad is technology. Learning is content. Technology should enable, not disable; the participation of the students interactively will replace the old lecturing format. Traditional educators will embrace this new approach in education. The transition will come steadily by newer teachers joining the education domain. Traditional teachers can start by using hybrid methodologies (combination of traditional and technology) in order to transit slowly.

ix. Working together can be excruciating, so eliminating personnel barriers could result in a good cooperation/collaboration;

x. All teams will have flaws and virtues. The most important bit is the team dynamics, with a good equilibrium between disciplines. A sum of solo players never makes a good team.

xi. Create relevant contents. It is very important to create consistent information in order to make good sense of it. If doctors, therapists, psychologists, engineers, etc., join together to develop applications for health, great things would be made.

xii. Build channels to reach all over the world. We are part of something and we have to take accountability towards the world as a community altogether Since e-learning started, education scientists are working with better, and better ways of distance learning

xiii. Bridging programs can be very useful after a first graduation course where the main abilities from one area are already consolidated. It is important to create complicity with people who compliment us with other knowledge, and thus, lead to join all skills that are needed to solve the problems we all have to deal with. Bridging program courses are the future in education. 
PAPER

xiv. An A-team has: commitment to the team goals (not only personal projects), respect for everybody's contribution, and mentoring from the more experienced ones to the least experienced ones. One should lead by example. Showing how you do it yourself is the best way to create the right culture of doing things; mutual understanding, patience, trust, persistence, and good communication.

xv. Psychologists are helpful in teams. They are mediators who usually understand everyone's position; and analyze people and figure out the best way to make them overcome difficulties. If we have a person like this on a team it will be easier to maintain proper relationships between all team members and to deal with conflicts that may occur. This is especially important for interdisciplinary and intercultural teams. A psychologist is the expert on human behavior, relationships, conflict resolution, and stress management.

xvi. A dream university is the one that has pleasant and large spaces to be used by people and to inspire them; less politics; less trade of influences; more values; free; able to inspire students, instead of just providing dry knowledge and skills only for jobs seeking; a great tradition; excellent professors; and demanding levels of performance.

We need people who have the imagination and intelligence to tackle future problems, and lead. Not strict professionals with confined knowledge linked only to their profession. Project Gutenberg allows students to download thousands of classic books to be read on any number of free book reader apps available. This seems a good example of a good teamwork between literature writers, programmers and designers.

\section{REFERENCES}

[1] Davies, W. M. (2009). Group work as a form of assessment: Common problems and recommended solutions. Higher Education, 58, 563-584. http://dx.doi.org/10.1007/s10734-009-9216-y
[2] Frasen, J. (2012). Teaming up for learning: Team effectiveness in collaborative learning in higher education. Proefschrifmaken.nl: Uitgeverij BOXPress.

[3] Foels, R., Driskell, J. E., Mullen, B., \& Salas, E. (2000). The effects of demographic leadership on group member satisfaction: An integration. Small Group Research, 31, 676-701. http://dx.doi.org/10.1177/104649640003100603

[4] Klein, K., Knight,A., Ziegert, J., Lim, B., \& Saltz, J. (2011). When team members'values differ:The moderating role of team leadership. Organizational Behavior and Human Decision Processes, 114, 25-36. http://dx.doi.org/10.1016/j.obhdp.2010.08.004

[5] Hamilton, B., \& Nikerson, J. \& Owan, H. (2003). Team incentives and worker heterogeneity: An empirical analysis of the impact of teams on productivity and participation. Journal of Political Economy, 111(3), 465-497. http://dx.doi.org/10.1086/374182

[6] Hughes, J.C. (2002). Tools and Techniques for Enchancing the quality and Effectiveness of Student Teams. Paper presented at the meeting 2002 HERDSA Conference: Quality Conversations, Perth, WA: Australia.

[7] Shimazoe, J. \& Aldrich, H. (2010). Group work can be gratifying: Understanding and overcoming resistance to cooperative learning. College Teaching, 58, 52-57. http://dx.doi.org/10.1080/8756755 0903418594

[8] Storm, P.S. \& Storm, R.D. (2002). Overcoming limitations of cooperative learning among community college students. Community College Journal of Research and Practice, 26, 315-331. http://dx.doi.org/10.1080/106689202753546466

[9] Zacarro, S. J. (1996). Social contextual considerations of efficacy beliefs: Defining multiple forms of social efficacy. Keynote address presented at the annual meeting of the Association for the Advancement of Applied Sport Psychology.

\section{AUTHORS}

Luísa Soares, PhD is Assistant Professor of Psychology at University of Madeira/ Madeira Interactive Technologies Institute, in Portugal, Europe (lsoares@uma.pt).

Dulce Pacheco, is a $\mathrm{PhD}$ student doing research in the area of Psychology and leadership.

This work was supported by Larsys (Robotic and Systems in Engineering and Science) and Madeira Interactive Technologies Institute. It is an extended and modified version of a paper presented at ICELW 2014, the Seventh Annual International Conference on E-learning in the Workplace, held from June 11-13, 2014 in New York. Submitted 09 January 2014. Published as resubmitted by the authors 14 October 2014. 